\title{
Skeletal Muscle Troponin I (Tnl) in Animal Fat Tissues to Be Used as Biomarker for the Identification of Fat Adulteration
}

\author{
Bong-Sup Park ${ }^{1}$, Young-Kyoung $\mathrm{Oh}^{2}$, Min-Jin $\mathrm{Kim}^{2}$, and Won-Bo Shim* \\ Food Analysis Research Team, Industry Service Research Center, World Institute of Kimchi, Gwangju 500-360, Korea \\ ${ }^{1}$ Department of Nutrition, Food and Exercise Sciences, Florida State University, Florida 32306-1493, USA \\ ${ }^{2}$ School of Physics and Chemistry, Gwangju Institute of Science and Technology, Gwangju 500-712, Korea
}

\begin{abstract}
In this study, the existence of skeletal muscle troponin I (smTnI), well-known as a muscle protein in fat tissues, and the utilization of smTnI as a biomarker for the identification of fat adulteration were investigated. A commercial antibody (ab97427) specific to all of animals smTnI was used in this study. Fat and meat samples (cooked and non-cooked) of pork and beef, and chicken considered as representative meats were well minced and extracted by heating and non-heating methods, and the extracts from fat and meat tissues were probed by the antibody used in both enzyme-linked immunosorbent assay (ELISA) and immunoblot. The antibody exhibited a strong reaction to all meat and fat extracts in ELISA test. On the other hand, the results of immunoblot analsis revealed a $23 \mathrm{kDa}$ high intensity band corresponding to the molecular weight of smTnI $(23786 \mathrm{Da})$. These results demonstrate that the existence of smTnI in all animal fat tissues. Since there are monoclonal antibodies specific to each species smTnI, smTnI in fat tissues could be used as a biomarker to identify or determine animal species adulterated in meat products. Therefore, an analytical method to identify fraudulent fat adulteration can be developed with an antibody specific to each species smTnI.
\end{abstract}

Keywords: skeletal muscle troponin I, fat tissue, anti-smTnI antibody, meat adulteration, fat species identification

\section{Introduction}

Fat tissue, generally called adipose tissue, is a kind of loose connective tissue composed of mature adipocytes, fibroblasts, immune cells, adipose tissue matrix and blood vessels. Its main role is to store energy in the form of fat, and it provides an unlimited storage place for triglycerides (Ahima and Flier, 2000; Kershaw and Flier, 2004). In fat tissue, approximately 60 to $85 \%$ of the weight of fat tissue is lipid with $90-99 \%$ being triglyceride, and the lipid is composed of six fatty acids, such as myristic, plamitic, palmitoleic, stearic, oleic, and linoleic. The remains of adipose tissue are composed of water (5 to $30 \%$ ) and protein (2 to 3\%) (Schaffler et al., 2012). Most proteins well studied are related to diseases, obesity, and diabetes in human. On the other hand, fat tissue has also been shown to secrete contractile proteins including myosin, tropomyosin-2, tropomyosin $\alpha-3$, and tropomyosin $\alpha-4$

\footnotetext{
*Corresponding author: Won-Bo Shim, Food Analysis Research Team, Industry Service Research Center, World Institute of Kimchi, Gwangju 500-360, Korea. Tel: +82-62-610-1759, Fax: +82-62-610-1850, E-mail: wbshim@wikim.re.kr
}

(Ahmed et al., 2009; Rosenow et al., 2010). Troponin I (TnI) has been classified as muscle protein in the past years. Moses et al. (1999) reported that TnI is present in human cartilage, and the authors explained that the role of $\mathrm{TnI}$ in cartilages is a potent and specific inhibitor of angiogenesis in vivo and in vitro. Yang et al. (2010) reported the TnI gene expression in porcine adipose (fat) tissue. Therefore, recent investigations mentioned above provide us the possibility of $\mathrm{TnI}$ presence in adipose tissue. However, to the best of our knowledge, the presence and expression of $\mathrm{TnI}$ in adipose tissue have never been reported.

The current study reports the existence of $\mathrm{smTnI}$ in animal fat tissues by enzyme-linked immunsorbent assay (ELISA) and immunoblot based on a commercial antibody specific to smTnI. Several researches reported monoclonal antibodies specific to species smTnI (Chen et al., 2010; Chen and Hsieh, 2002; Liu et al., 2006). With the monoclonal antibodies reported in previous studies (Chen et al., 2010; Chen and Hsieh, 2002; Liu et al., 2006) and the results reported in the current study, the presence of smTnI in each species fat tissue gives us an opportunity to develop an immunochemical method to identify fraud- 
ulent adulteration of fat tissues in meat products and foods.

\section{Materials and Methods}

\section{Materials and reagents}

Protein assay kit II, Mini-Protein 3 electrophoresis cell, power supply (PowerPac ${ }^{\mathrm{TM}}$ Basic), nitrocellulose membrane, goat anti-mouse IgG-alkaline phosphatase conjugate, and AP Conjugate Substrate kit were purchased from Bio-Rad Laboratories Inc. (Hercules, USA). Bovine serum albumin (BSA), horseradish peroxidase conjugated goat anti-mouse IgG, and ABTS (2'-azino-di-[3-ethyl-benothyazoline-6-sulfonic acid]) were obtained from SigmaAldrich Co. (USA). Broad-range Pre-stained Marker obtained from ELPIS (Korea). GelCodeTM Blue Safe protein Stain was obtained from Thermo Fisher Scientific Inc. (USA). Ninety six well polystyrene microplates was purchased from Greiner Bio-One (Germany). Filters (Whatman No. 1 paper) were purchased from Fisher Scientific (USA). Microplate reader (Model Infinite ${ }^{\circledR} 200$ PRO NanoQuant) was purchased from TECAN (Switzerland). 10X Tris/Glycine/SDS and 10X Tris/Glycine/(w/o) SDS buffers were obtained from Biosesang (Korea).

All solutions were prepared with distilled deionized pure water (DD water) from a Purelab Option Water Purification System (ELGA, UK). All chemicals and reagents used were analytical grade.

An anti-Troponin I fast skeletal muscle antibody (ab 97427) used as a probe in the study and standard Troponin I fast skeletal muscle full length protein (ab9919) were purchased from abcam (UK).

\section{Preparation of meat and fat samples}

Fat and meat samples of pork and beef, and chicken considered as representative meats were obtained from local supermarkets. Pure fat tissues were prepared by trimming off visible meat and connective tissues. Also, visible fat and connective tissues were trimmed off for lean meat samples. The fat and meat samples were then ground well and stored at $-20^{\circ} \mathrm{C}$ until use. The ground fat or meat samples were heated for $10 \mathrm{~min}$ at boiling water $\left(100^{\circ} \mathrm{C}\right)$ and used as cooked fat and meat samples. Raw fat or meat samples were prepared as raw samples without any further treatment.

\section{Protein extraction}

In order to extract target protein from adipose tissue, an extraction method with and without heating treatment was chosen, and the protein amount extracted by both methods was compared. First, for extracting protein from raw and cooked fat samples and cooked meat samples without heating treatment, both raw and cooked fat samples and cooked meat samples $(20 \mathrm{~g})$ were mixed with $0.5 \mathrm{M} \mathrm{NaCl}(40 \mathrm{~mL})$, kept at $4^{\circ} \mathrm{C}$ for $30 \mathrm{~min}$, and centrifuged at 5,000 rpm for $15 \mathrm{~min}$ at $4^{\circ} \mathrm{C}$. The supernatants were filtered through Whatman No. 1 filter paper and stored at $-20^{\circ} \mathrm{C}$ before use. Second, the extraction of protein from raw and cooked fat and cooked meat samples by heating treatment was performed by the same mentioned above with exception that the fat and meat in 0.5 $\mathrm{M} \mathrm{NaCl}$ were heated at boiling water for $15 \mathrm{~min}$ before the centrifugation.

Meanwhile, raw meat samples (20 g) were further diluted with $100 \mathrm{~mL}$ of $0.5 \mathrm{M} \mathrm{NaCl}$, as raw meat samples often formed Jelly (especially raw chicken meat) after homogenizing. Therefore, all raw meat samples were mixed with $200 \mathrm{~mL}$ of $0.5 \mathrm{M} \mathrm{NaCl}$. The remaining procedures for extracting protein from raw meat samples with and without heating were the same with those of raw and cooked fat and cooked meat samples. The total amount of protein extracted from the raw and cooked fat and meat samples were determined and compared.

\section{ELISA processes}

In order to determine the presence of smTnI in adipose tissue, an indirect ELISA based on the commercial antibody (ab97427) was first carried out. Wells of polystyrene microplates were coated with $5 \mu \mathrm{g}$ of soluble crude

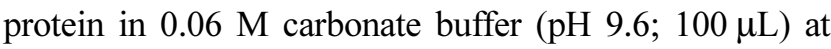
$37^{\circ} \mathrm{C}$ for $1 \mathrm{~h}$ and then washed 3 times with $0.01 \mathrm{M}$ phosphate buffer saline (PBS; pH 7.2) containing 0.05\% (v/v) Tween-20 (PBST) using a microplate washer. 1\% BSA $(200 \mu \mathrm{L})$ was added into the wells of plates and incubated overnight at $4^{\circ} \mathrm{C}$ to minimize nonspecific binding, followed by a further washing (4 times). One hundred microliters of properly diluted the antibody $(1 / 3,000)$ in PBS were separately dispensed into the wells and incubated at $37^{\circ} \mathrm{C}$ for $1 \mathrm{~h}$. After washing 4 times, $100 \mu \mathrm{L}$ of horseradish peroxidase conjugated goat anti-mouse $\mathrm{IgG}$ diluted 1:3000 in PBS was added to the wells, incubated at $37^{\circ} \mathrm{C}$ for $1 \mathrm{~h}$, and additionally washed 5 times. One hundred microliters of substrate solution (1 mg of 2,2'-azino-di[3-ethyl-benothyazoline-6-sulfonic acid] and $7 \mu \mathrm{L}$ of $30 \%$ hydrogen peroxide in $10 \mathrm{~mL}$ of $0.1 \mathrm{M}$ citrate buffer, $\mathrm{pH}$ 4.0) was added into the wells and then incubated at $37^{\circ} \mathrm{C}$ for $30 \mathrm{~min}$. The enzyme reaction was stopped by adding $100 \mu \mathrm{L}$ of $1 \mathrm{~N} \mathrm{H}_{2} \mathrm{SO}_{4}$ to the wells, and the absorbance 
was measured by a microplate reader at $405 \mathrm{~nm}$.

Sodium dodecyl dulfate-polyacrylamide gel electrophoresis (SDS-PAGE)

SDS-PAGE for determining and comparing the protein profiles extracted from fat and meat samples was performed by the method of Laemmli (1970) with slight modifications. Briefly, the sample extracts ( $8 \mu \mathrm{g}$ of protein in $10 \mu \mathrm{L}$ per well) and the prestained broad range protein marker ( $4 \mu \mathrm{L}$ per well) were loaded into wells of a $5 \%$ stacking gel and separated on a $12 \%$ polyacrylamide separating gel. Electrophoresis was performed at $150 \mathrm{~V}$ for $1.5 \mathrm{~h}$ by using a Mini-Protein 3 electrophoresis cell (Bio$\mathrm{Rad}$ ) connected to a power supply. The separating gel was stained with GelCodeTM Blue Safe protein Stain solution (Thermo Scientific) and destained by distilled water. Analysis of protein on gel was estimated by visual observation.

\section{Immunoblot analysis}

Immunoblot analysis using the antibody (ab97427) were performed to confirm the presence of smTnI in adipose tissue. Briefly, all proteins on the $12 \%$ separating gel were transferred into nitrocellulose membranes with 100 $\mathrm{V}$ for $1 \mathrm{~h}$. The membranes were rinsed with deionized water and blocked with $1 \%$ BSA/PBS overnight with rocking at $4^{\circ} \mathrm{C}$. The blocked membranes were then washed twice in PBST and incubated with the antibody (ab97427) diluted $(1 / 3000)$ in $1 \% \mathrm{BSA} / \mathrm{PBS}$ for $1 \mathrm{~h}$ at room temperature on a rocker. The membranes were washed with PBST 4 times to remove the excess antibodies and incubated with goat anti-mouse IgG-HRP conjugate diluted 1:3000 in $1 \% \mathrm{BSA} / \mathrm{PBS}$ for $1 \mathrm{~h}$ at room temperature on a rocker. After incubating and washing membrane 4 times with PBST, the color was developed by adding AP Conjugate Substrate kit solution (Bio-Rad Laboratories) and stopped by washing with distilled water for $10 \mathrm{~min}$ with gentle agitation. The blot was obtained on a membrane and analyzed by visual observation. The appearance of purplish blots indicated the location of the antibody (ab97427) bound to the smTnI.

\section{Results and Discussion}

\section{Determination of protein amount extracted from fat and meat samples}

Protein extracts of both raw and cooked fat tissue and lean meat were extracted by heating and non-heating methods and used to quantify the total amount of extracted proteins. Table 1 shows the kinds and conditions of fat and

Table 1. The lists of sample extracts used and their abbreviations

\begin{tabular}{|c|c|c|c|c|}
\hline & & Conditions of sample & Methods for sample extraction & Abbreviation used in this study \\
\hline \multirow{8}{*}{ Pig } & \multirow{4}{*}{ Fat } & Raw & \multirow{2}{*}{ Non-heating } & PFRC \\
\hline & & Cooked & & PFCC \\
\hline & & Raw & \multirow{2}{*}{ Heating } & PFRH \\
\hline & & Cooked & & $\mathrm{PFCH}$ \\
\hline & \multirow{4}{*}{ Meat } & Raw & \multirow{2}{*}{ Non-heating } & PMRC \\
\hline & & Cooked & & PMCC \\
\hline & & Raw & \multirow{2}{*}{ Heating } & PMRH \\
\hline & & Cooked & & $\mathrm{PMCH}$ \\
\hline \multirow{8}{*}{ Beef } & \multirow{4}{*}{ Fat } & Raw & \multirow{2}{*}{ Non-heating } & BFRC \\
\hline & & Cooked & & $\mathrm{BFCC}$ \\
\hline & & Raw & \multirow{2}{*}{ Heating } & BFRH \\
\hline & & Cooked & & $\mathrm{BFCH}$ \\
\hline & \multirow{4}{*}{ Meat } & Raw & \multirow{2}{*}{ Non-heating } & BMRC \\
\hline & & Cooked & & BMCC \\
\hline & & Raw & \multirow{2}{*}{ Heating } & BMRH \\
\hline & & Cooked & & $\mathrm{BMCH}$ \\
\hline \multirow{8}{*}{ Chicken } & \multirow{4}{*}{ Fat } & Raw & \multirow{2}{*}{ Non-heating } & CFRC \\
\hline & & Cooked & & $\mathrm{CFCC}$ \\
\hline & & Raw & \multirow{2}{*}{ Heating } & CFRH \\
\hline & & Cooked & & $\mathrm{CFCH}$ \\
\hline & \multirow{4}{*}{ Meat } & Raw & \multirow{2}{*}{ Non-heating } & CMRC \\
\hline & & Cooked & & CMCC \\
\hline & & Raw & \multirow{2}{*}{ Heating } & $\mathrm{CMRH}$ \\
\hline & & Cooked & & $\mathrm{CMCH}$ \\
\hline
\end{tabular}


meat samples. A total of 12 fats (PFRC, PFCC, PFRH, $\mathrm{PFCH}, \mathrm{BFRC}, \mathrm{BFCC}, \mathrm{BFRH}, \mathrm{BFCH}, \mathrm{CFRC}, \mathrm{CFCC}$, $\mathrm{CFRH}$, and $\mathrm{CFCH}$ ) and 12 meats (PMRC, PMCC, PMRH, $\mathrm{PMCH}, \mathrm{BMRC}, \mathrm{BMCC}, \mathrm{BMRH}, \mathrm{BMCH}, \mathrm{CMRC}, \mathrm{CMCC}$, $\mathrm{CMRH}$, and $\mathrm{CMCH}$ ) extracts were prepared. Protein concentrations of the extracts were shown in Table 2. Protein amounts from chicken fat and meat were significantly higher than those of pork and beef. On the other hand, the protein amounts from fat samples were much lesser than meat samples. This outcome is expected as meats largely comprise of various proteins. Ratios of protein amount (fat: meat) were approximately 1:4.7 - 1:8.7 for raw samples and 1:5.3 - 1:41.5 for cooked samples. Among four groups of the extracts with different sample conditions (raw and cooked) and extraction methods (heating and non-heating treatment), raw fat (PFRC, BFRC, and CFRC) and meat (PMRC, BMRC, and CMRC) samples extracted with non-heating treatments including cooking showed higher protein amount than the others (fat; PFCC, PFRH, $\mathrm{PFCH}, \mathrm{BFCC}, \mathrm{BFRH}, \mathrm{BFCH}, \mathrm{CFCC}, \mathrm{CFRH}$, and $\mathrm{CFCH}$, meat; PMCC, PMRH, PMCH, BMCC, BMRH, BMCH, $\mathrm{CMCC}, \mathrm{CMRH}$, and $\mathrm{CMCH}$ ) treated with cooking and heating steps, and their protein amounts (PFRC, BFRC, CFRC, PMRC, BMRC, and CMRC) are 6.2-58.5 times higher than those of the extracts from cooked meat and fat samples by non-heating treatment (PFCC, BFCC, CFCC, PMCC, BMCC, and CMCC). For cooked fat and meat samples, the extracts with heating treatment $(\mathrm{PFCH}, \mathrm{BFCH}$, $\mathrm{CFCH}, \mathrm{PMCH}, \mathrm{BMCH}$, and $\mathrm{CMCH}$ ) possessed much higher protein amount than those of cooked fat and meat samples extracted by non-heating treatment (PFCC, BFCC, CFCC, PMCC, BMCC, and CMCC). With these results, heating treatment is suitable for cooked fat and meat samples, whereas non-heating treatment is useful for raw fat and meat samples. However, these results do not mean the efficiency of smTnI extraction, and the efficiency of target protein extraction by heating and non-heating treatments was validated by ELISA and immunoblot analysis.

\section{SDS-PAGE analysis}

After proteins being extracted from fat and meat samples, various soluble proteins including smTnI may be included in the extracts. The protein profiles for the fat and meat extracts were analyzed by SDS-PAGE with 5\% stacking and 15\% separating gels. Fig. 1 shows the gels of SDS-PAGE for the protein pattern of fat and meat extracts of pork (Fig. 1a), beef (Fig. 1b), and chicken (Fig. 1c) by non-heating and heating methods. After cooking

Table 2. Protein extracted from fat and meat samples

\begin{tabular}{|c|c|c|c|c|}
\hline $\begin{array}{l}\text { Sample } \\
\text { extracts }\end{array}$ & $\begin{array}{c}\text { Total protein in extracts } \\
(\mathrm{mg})\end{array}$ & $\begin{array}{c}\text { Initial sample weight } \\
(\mathrm{g})\end{array}$ & $\begin{array}{l}\text { Protein concentration } \\
(\mathrm{mg} / \mathrm{g})\end{array}$ & $\begin{array}{l}\text { Ratio of protein amount extracted } \\
\text { between fat and meat (fat : meat) }\end{array}$ \\
\hline PFRC & $76.14 \pm 1.37$ & 10 & $7.61 \pm 0.14$ & \multirow{2}{*}{$1: 6.2$} \\
\hline PMRC & $473.40 \pm 14.56$ & 10 & $47.34 \pm 1.46$ & \\
\hline PFCC & $1.32 \pm 0.12$ & 10 & $0.13 \pm 0.01$ & \multirow{2}{*}{$1: 28.5$} \\
\hline PMCC & $37.05 \pm 0.35$ & 10 & 3.71 & \\
\hline PFRH & $4.49 \pm 0.21$ & 10 & $0.45 \pm 0.02$ & \multirow{2}{*}{$1: 6.9$} \\
\hline PMRH & $31.20 \pm 1.26$ & 10 & $3.10 \pm 0.13$ & \\
\hline PFCH & $3.19 \pm 0.15$ & 10 & $0.32 \pm 0.01$ & \multirow{2}{*}{$1: 5.3$} \\
\hline $\mathrm{PMCH}$ & $17.01 \pm 0.47$ & 10 & $1.70 \pm 0.05$ & \\
\hline BFRC & $56.62 \pm 4.24$ & 10 & $5.66 \pm 0.42$ & \multirow{2}{*}{$1: 8.7$} \\
\hline BMRC & $494.30 \pm 12.86$ & 10 & $49.43 \pm 1.29$ & \\
\hline $\mathrm{BFCC}$ & $2.32 \pm 0.17$ & 10 & $0.23 \pm 0.02$ & \multirow{2}{*}{$1: 14.4$} \\
\hline $\mathrm{BMCC}$ & $33.05 \pm 1.14$ & 10 & $3.31 \pm 0.11$ & \\
\hline BFRH & $5.77 \pm 0.26$ & 10 & $0.58 \pm 0.03$ & \multirow{2}{*}{$1: 6.8$} \\
\hline BMRH & $39.61 \pm 1.57$ & 10 & $3.96 \pm 0.16$ & \\
\hline $\mathrm{BFCH}$ & $2.73 \pm 0.05$ & 10 & $0.27 \pm 0.01$ & \multirow{2}{*}{$1: 10.2$} \\
\hline $\mathrm{BMCH}$ & $27.50 \pm 1.81$ & 10 & $2.75 \pm 0.18$ & \\
\hline CFRC & $144.27 \pm 29.72$ & 10 & $14.43 \pm 2.97$ & \multirow{2}{*}{$1: 4.7$} \\
\hline CMRC & $678.70 \pm 47.06$ & 10 & $67.87 \pm 4.71$ & \\
\hline $\mathrm{CFCC}$ & $2.56 \pm 0.39$ & 10 & $0.26 \pm 0.04$ & \multirow{2}{*}{$1: 41.5$} \\
\hline $\mathrm{CMCC}$ & $108.04 \pm 0.21$ & 10 & $10.80 \pm 0.02$ & \\
\hline CFRH & $8.51 \pm 0.50$ & 10 & $0.85 \pm 0.05$ & \multirow{2}{*}{$1: 7.3$} \\
\hline CMRH & $61.96 \pm 1.32$ & 10 & $6.20 \pm 0.13$ & \\
\hline $\mathrm{CFCH}$ & $5.26 \pm 0.90$ & 10 & $0.53 \pm 0.09$ & \multirow{2}{*}{$1: 10.3$} \\
\hline $\mathrm{CMCH}$ & $54.37 \pm 0.98$ & 10 & $5.44 \pm 0.10$ & \\
\hline
\end{tabular}




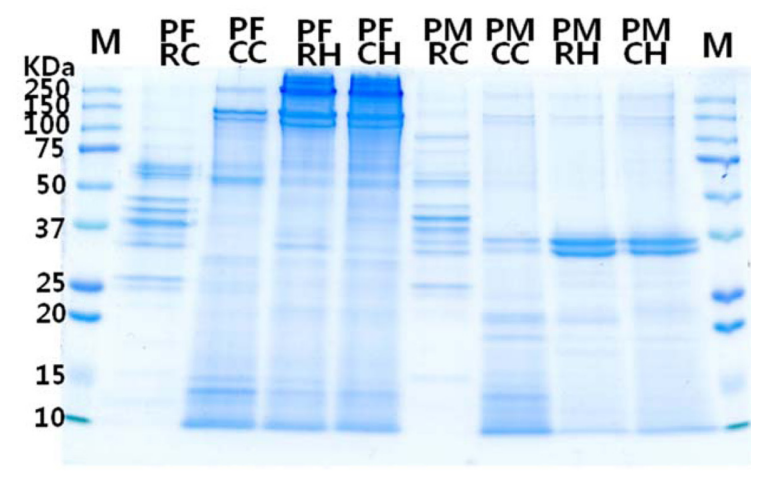

(a)

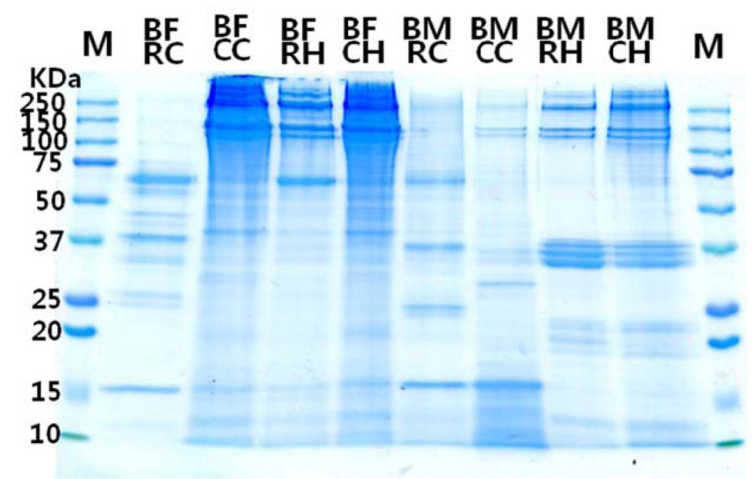

(b)

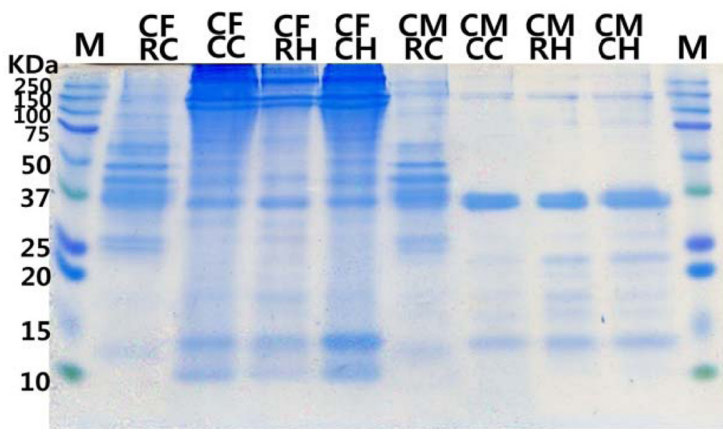

(c)

Fig. 1. SDS-PAGE of cooked and raw pork (a), beef (b), and chicken (c) meat and fat extracts with and without heating treatment. Lane $\mathrm{M}$ : protein marker.

and heating fat and meat, the protein profiles were significantly different from the raw fat and meat samples without cooking and heating steps. In case of pork fat, the PFRC extract showed major protein bands ranged of 25 to $60 \mathrm{kDa}$, whereas the PFCC, PFRH and PFCH extracts showed similar protein profiles with several major bands $>50 \mathrm{kDa}$ and $<15 \mathrm{kDa}$. On the other hand, the protein profile of PMRC was very similar to that of PFRC and significantly differed from the extracts of PMCC, PMRH, and $\mathrm{PMCH}$ which are cooked or heated. Cooked pork meat extracts by heating treatment exhibited a major band around $33 \mathrm{kDa}$, which is considered as a tropomyosin that is known as thermal-stable protein (Fig. 1a). The extracts from cooked and raw beef fat and meat samples were similar in protein profile to those of pork (Fig. 1b). The protein profiles of CFRC and CMRC were almost the same, but the cooked and heated fat extracts (CFCC, $\mathrm{CFRH}$ and $\mathrm{CFCH}$ ) exhibited different protein profiles from the cooked and heated meat extracts (CMCC, CMRH and $\mathrm{CMCH}$ ). Protein bands at $33 \mathrm{kDa}$ were also observed in all chicken fat and meat extracts (Fig. 1c).

We expected that various protein profiles will be obtained from the fat extracts without cooking and heating treatment (PFRC, BFRC, and CFRC). However, cooked and heated fat samples showed various protein profiles in SDS-PAGE analyses. We assumed that various thermal stable proteins may exist in adipose tissues. In addition, soluble and non-thermal stable proteins in adipose tissue, which is not target protein (smTnI) may be denatured to insoluble proteins by cooking and heating and could be removed by centrifugation and filtration. Therefore, a greater quantity of thermal stable protein including $\mathrm{TnI}$ and tropomyosin known as thermal stable protein might be contained in the extracts obtained by heating treatment.

\section{Determination of smTnI in fat tissues by ELISA}

Three meat extracts (PMRH, BMRH, and CMRH) and 12 fat extracts (PFRC, PFCC, PFRH, PFCH, BFRC, BFCC, $\mathrm{BFRH}, \mathrm{BFCH}, \mathrm{CFRC}, \mathrm{CFCC}, \mathrm{CFRH}$, and $\mathrm{CFCH}$ ) were tested to identify the presence of smTnI in adipose tissue by ELISA. Fig. 2 shows the results of ELISA based on the commercial antibody (ab97427). The antibody reacted strongly to most of fat and meat extracts, but less reacted to PFCC, which showed lower protein concentration in the extracts $(0.13 \mathrm{mg} / \mathrm{g})$. ELISA results indicated that smTnI subsists not only in meat but also in fat tissues. The extracts (PFRH, PFCH, BFRH, BFCH, CFRH, and $\mathrm{CFCH}$ ) obtained from cooked and raw fats by heating treatment showed high reading values in the ELISA, we assume that the smTnI in adipose tissue would be more concentrated in the extracts with heating treatment as more heat labile proteins will be eliminated. This meant that the most efficient method for extracting smTnI from raw fat tissues was via heating treatment. Therefore, we suppose that a greater quantity of smTnI might be contained in the extracts by heating treatment, even if the protein amount in fat extracts by heating treatment was much lesser than that of raw fat extracts without heating. Thus, the extracts (PFRH, PMRH, BFRH, BMRH, CFRH, and CMRH) from rat fat and meat by heating method was used for 


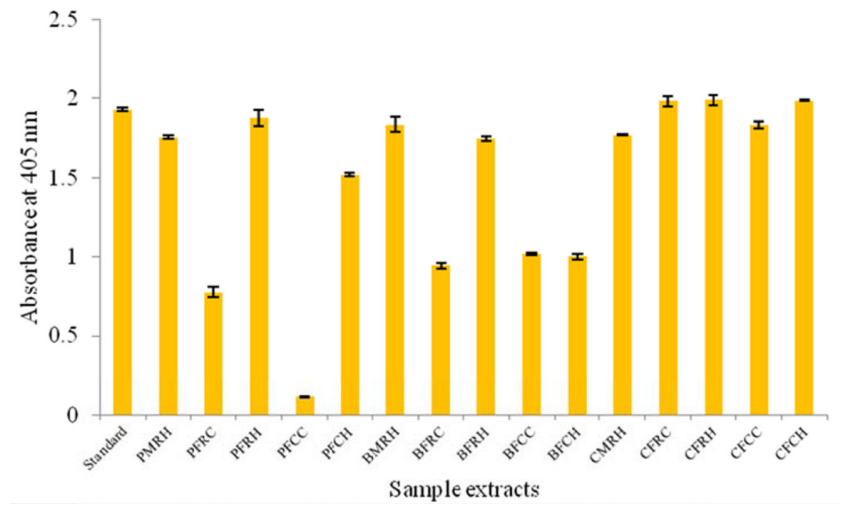

Fig. 2. ELISA results showing specific binding of a commercial antibody (ab 97427) to animal skeletal muscle TnI extracted from meat and fat tissues.

immunoblot analysis.

Identification of the presence of smTnI in fat tissues Representative three fat extracts (PFRH, BFRH, and $\mathrm{CFRH}$ ) and three meat extracts (PMCC, BMCC, and CMCC) showing higher O.D. values in the ELISA were used for immunoblot analysis. Fig. 3 shows the result of immunoblot analaysis. The antibody (ab97427) gave us a band at $23 \mathrm{kDa}$ for all lanes loaded with fat and meat extracts of pork, beef, and chicken. Consequentially, it is reasonable to hypothesize that smTnI, previously considered a muscle-specific protein, also exists in fat tissues.

The presence of smTnI will be received great attention because troponin I has been well established as a cardiac and skeletal muscle-specific protein while its expression in adipose tissue remained unknown. Therefore, smTnI was never regarded as a potential biomarker in fat tissue. In previous studies (Chen et al., 2010; Chen and Hsieh, 2002; Liu et al., 2006), monoclonal antibodies specific to smTnI of pork and beef were developed and exhibited strong reaction specifically to the $24 \mathrm{kDa}$ thermo-stable smTnI of pork. We suppose that an immuno assay based on the monoclonal antibodies specific to each species smTnI could be developed for the identification of fat adulteration in meat products. In practice, immunochemical methods for the detection of fat adulteration in meat products have not been reported yet. Therefore, the results obtained in this study gives us an opportunity that an immunochemical method to identify adulteration of fat tissues in meat products can be developed with smTnI in fat tissues.

In this study, we investigated the presence of smTnI in fat tissues. For this study, the extraction methods with and

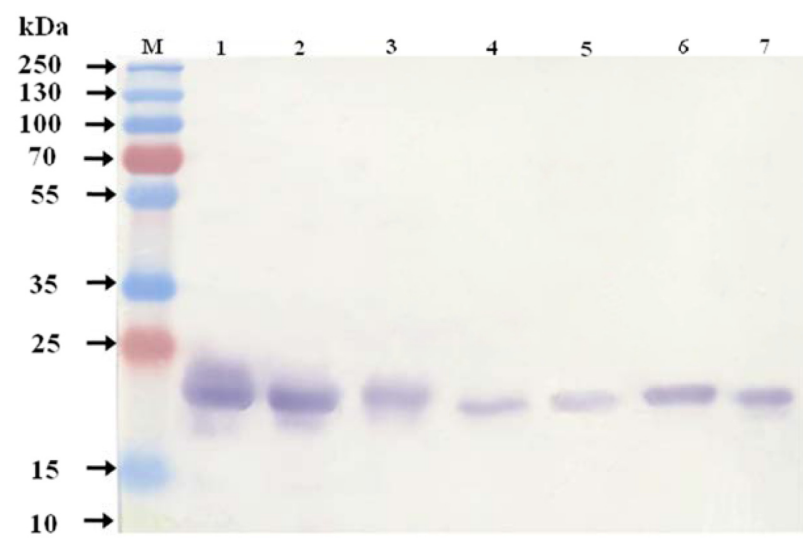

Fig. 3. Representative immunoblot showing specificity of a commercial antibody (ab 97427) for meat and fat extracts from different species. Lane $M$ protein marker, lane 1: standard of skeletal muscle TnI, lane 2: PMRH, lane 3: PFRH, lane 4: BMRH, lane 5: BFRH, lane 6: CMRH, lane 7: CFRH.

without heating treatment were tested, and heating method to extract target protein (smTnI) from fat tissue was confirmed to be most efficiency. The existence of smTnI in adipose tissue were confirmed by ELISA and immunoblot analysis based on the commercial antibody (ab97427) that is specific to all animals smTnI. The results obtained from both methods provide solid evidence of the existence of smTnI in animal fat tissues. To our knowledge, the current study is the first report that explores the presence of smTnI in fat tissues.

In this study, we did not investigate the function of smTnI in fat tissues, but further research is needed to investigate function of smTnI in animal fat tissue. In addition, smTnI may potentially serve as an efficient marker for the detection of fat species in meat and food products via immunochemical techniques. Fat tissues are major byproducts obtained from meat processing and is often used as an ingredient in meat and food products to gain extra profits such as flavor and weight. However, food containing unclear fat tissues may cause serious concerns in the view of some religions such as Islam and Judaism, and for vegetarians. With these results, we expect that a rapid and reliable tool based immunochemical method could be developed to quantitatively detect unlabeled fat adulteration in meat products and processed foods. In this study, the presence of skeletal muscle troponin I (smTnI) in fat tissue of several mammalians was demonstrated. Actually, we have developed immunoassays based on monoclonal antibodies specific to pork fat tissue produced from mice immunized with the pork fat extracts prepared in the cur- 
rent manuscript. This demonstrated that the smTnI in fat tissues could be also used as good immunogen to produce antibodies specific to fat tissue of each species.

\section{Acknowledgements}

This research was also supported by the Basic Science Research Program through the NRF funded by the Ministry of Education (NRF-2013R1A1A2007484).

\section{References}

1. Ahima, R. S. and Flier, J. S. (2000) Adipose tissue as an endocrine organ. Trends Endocrin. Met. 11, 327-332.

2. Ahmed, M., Neville, M. J., Edelmann , M. J., Kessler, B. M., and Karpe, F. (2009) Proteomic analysis of human adipose tissue after rosiglitazone treatment shows coordinated changes to promote glucose uptake. Obesity 18, 27-34.

3. Chen, F. C. and Hsieh, Y. H. P. (2002) Porcine troponin I: a thermostable species marker protein. Meat Sci. 61, 55-60.

4. Chen, F. C., Hsieh, Y. H. P., and Brigdman, R. C. (2004) Monclonal antibody-based sandwich enzyme-linked immunosorbent assay for sensitive detection of prohibited ruminant proteins in feedstuffs. J. Food Protect. 67, 544-549.

5. Kershaw, E. E. and Flier, J. S. (2004) Adipose tissue as an endocrine organ. J. Clin. Endocrinol. Metab. 89, 2548-2556.

6. Laemmli, U. K. (1970) Cleavage of structural proteins during the assembly of the head of bacteriophage T4. Nature 227, 680-685.

7. Liu, L., Chen, F. C., Dorsey, J. L., and Hsieh, Y. H. P. (2006) Sensitive monoclonal antibody-based sandwich ELISA for the detection of porcine skeletal muscle in meat and feed products. J. Food Sci. 71, M1-M6

8. Moses, M. A., Wiederschain, D., Wu, I., Fernandez, C. A., Ghazizadeh, V., Lane, W. S., Flynn, E., Sytkowski, A., Tao, T., and Lancer, R. (1999) Troponin I is present in human cartilage and inhibits angiogenesis. Proc. Natl. Acad. Sci. 96, 2645-2650.

9. Rosenow, A., Arrey, T. N., Bouwman, F. G., Noben, J. P., Wabitsch, M., Mariman, E. C., Karas, M., and Renes, J. (2010) Identification of novel human adipocyte secreted proteins by using SGBS cells. J. Proteome. Res. 9, 5389-5401.

10. Schaffler, A., Schölmerich, J., and Büchler, C. (2005) Mechanisms of disease: adipocytokines and visceral adipose tissue-emerging role in intestinal and mesenteric diseases. Nat. Clin. Pract. Gastroenterol. Hepatol. 2, 103-111.

11. Yang, H., Xu, Z., Ma, Z., Xiong, Y., Deng, C., and Zuo, B. (2010) Molecular cloning and comparative characterization of the porcine troponin I family. Anim. Biotechnol. 21, 64-76.

(Received 2014.7.13/Revised 2014.10.7/Accepted 2014.11.4) 